\title{
Katarzyna Drąg
}

Uniwersytet Papieski Jana Pawła II w Krakowie

\section{UMIĘDZYNARODOWIENIE BADAŃ MEDIOZNAWCZYCH I KSZTALCENIA AKADEMICKIEGO - STUDIUM PRZYPADKU}

\begin{abstract}
Internationalisation of media studies in higher education - case study. The article concerns the internationalization category currently in Polish higher education and in the global dimension. The advantages and challenges associated with this process are presented in the text in a form of case study of the internationalization of media research and media education at the Institute of Journalism and Social Communication of the Pontifical University of John Paul II in Krakow.

Umiędzynarodowienie badań medioznawczych i kształcenia akademickiego studium przypadku. Artykuł dotyczy aktualnej w polskim szkolnictwie wyższym oraz w wymiarze światowym kategorii umiędzynarodowienia. Zalety oraz wyzwania wiążące się z tym procesem zostały w tekście przedstawione w studium przypadku umiędzynaradawiania badań medioznawczych oraz kształcenia medialnego w Instytucie Dziennikarstwa i Komunikacji Społecznej Uniwersytetu Papieskiego Jana Pawła II w Krakowie.
\end{abstract}

Keywords internationalization in higher education, international projects, Institute of Journalism and Social Communication, international conferences in media studies umiędzynarodowienie w szkolnictwie wyższym, projekty międzynarodowe, Instytut Dziennikarstwa i Komunikacji Społecznej, medioznawcze konferencje międzynarodowe 
Wymiana doświadczeń pomiędzy państwami i kulturami w historii zawsze była motorem rozwoju społeczeństw. Uprawianie nauki wymaga szerokiego spojrzenia na zagadnienia i otwartości na różnorodność podejść badawczych do określonych problemów, które wynikają z odmiennych kontekstów społecznych, kulturowych, historycznych, metodologicznych. Proces umiędzynarodowienia nauki sprzyja wieloaspektowemu spojrzeniu na zagadnienia naukowe, również z zakresu nauki o mediach i komunikacji społecznej.

\section{UMIĘDZYNARODOWIENIE JAKO ŚWIATOWA I POLSKA TENDENCJA W SZKOLNICTWIE WYŻSZYM}

Jednym z głównych celów reformy szkolnictwa wyższego w Polsce jest zwiększenie poziomu umiędzynarodowienia polskiej nauki i polskich uniwersytetów. Umiędzynarodowienie jest główną siłą napędową rozwoju szkolnictwa wyższego na świecie. W Polsce powstała niedawno, w 2017 roku Narodowa Agencja Wymiany Akademickiej, której zadaniem jest wspieranie międzynarodowej wymiany akademickiej, wsparcie procesów umiędzynarodowienia polskich uczelni, a także wspieranie międzynarodowej wymiany naukowców w ramach umów i programów międzynarodowych i współpracy bilateralnej między uniwersytetami.

Obecny akcent na umiędzynarodowienie w szkolnictwie wyższym jest konsekwencją procesów zachodzących od ok. ćwierć wieku, które intensyfikowały się na przełomie XX i XXI wieku. „W wymiarze politycznym - pisze Dominik Antonowicz - pojawiają się [wtedy] inicjatywy współpracy międzynarodowej, takiej jak: inicjowanie Procesu bolońskiego (1999), stworzenie Europejskiego Obszaru Badawczego (2000), Europejskiego Obszaru Szkolnictwa Wyższego (2010), które z jednej strony doskonale odzwierciedlały kierunek zachodzących zmian społeczno-politycznych, a jednocześnie same wzmacniały ich dynamikę, zwłaszcza w kontekście postępującej harmonizacji europejskich systemów szkolnictwa wyższego" ${ }^{1}$.

Do wybranych obszarów umiędzynarodowienia zaliczyć trzeba umiędzynarodowienie nauki i wiedzy, networking międzynarodowy, umiędzynarodowienie wizerunku uczelni, umiędzynarodowienie studentów, umiędzynarodowienie pracowników administracyjnych, umiędzynarodowienie studiów ${ }^{2}$. Każdy z tych obszarów otwiera kolejne pola do analiz i szczegółowych refleksji. Pola te niejednokrotnie się przenikają.

Proces internacjonalizacji w szkolnictwie wyższym jest kwestią złożoną i wieloaspektową, którą analizować można z perspektyw: rozwojowej i przyszłościowej (analizując

${ }^{1}$ D. Antonowicz, Lepsze jutro było wczoraj, czyli mity dotyczące umiędzynarodowienia szkolnictwa wyższego, w: Czas internacjonalizacji II. Perspektywy, priorytety, projekty, red. B. Siwińska, G. Mazurek, Warszawa 2017, s. 17.

${ }^{2}$ Por. G. Mazurek, Zarządzanie uczelnia międzynarodowa - perspektywa krajowa - Akademia Leona Koźmińskiego, w: Czas internacjonalizacji. Wyzwania dla polskich uczelni, red. B. Siwińska, M. Zimnak, Warszawa 2016, s. 51. 
tendencje polskie i światowe), zarządczej (analiza procesów umiędzynarodowienia na wszystkich poziomach funkcjonowania uczelni wyższych) oraz operacyjnej (analiza konkretnych zrealizowanych projektów, które na zasadzie dobrych praktyk, mogą stanowić inspirację dla innych instytucji) ${ }^{3}$.

Mechanizmy umiędzynarodowienia są zależne od specyfiki poszczególnych uczelni, ich potencjału, wielkości, charakteru. Uniwersytet Papieski Jana Pawła II w Krakowie jest uczelnią młodą, a jednocześnie o wielowiekowej tradycji, z zasady uczelnią międzynarodową (z podwójną akredytacją: polską i watykańską), o profilu społeczno-humanistycznym (bez ekonomii i zarządzania w naukach społecznych). Można więc stwierdzić, że Uniwersytet nie prowadzi kierunków, które z zasady najłatwiej „podwyższają” poziom umiędzynarodowienia w szkolnictwie wyższym (np. medycyna). Jednocześnie jednak warto podkreślić, że Uniwersytet Papieski Jana Pawła II w Krakowie ma swoje ważne miejsce na rynku szkolnictwa wyższego w Polsce. Specyfika tej instytucji jest i powinna być jej zaletą (a do zalet należą m.in. kameralność, prestiż, możliwe ścisłe, partnerskie relacje nauczyciel-uczeń, wykorzystanie zaawansowanej infrastruktury - w przypadku kierunku dziennikarstwo i komunikacja społeczna jest nim Akademickie Centrum Medialne).

Wiedza o tendencjach globalnych związanych z internacjonalizacją nauki i edukacji umożliwia spojrzenie na konkretne działania jednostek uniwersyteckich w tym zakresie. Proces umiędzynarodowienia w szkolnictwie wyższym jest zależny od wielu czynników i z zasady nie przebiega identycznie w przypadku poszczególnych dyscyplin naukowych, zwłaszcza tych, które odnoszą się silnie do kultury lokalnej. W każdym przypadku internacjonalizacja jest możliwa, ale wymaga ona, co oczywiste, różnych podejść i przebiega odmiennymi torami. Poniżej przedstawione studium przypadku umiędzynarodawiania studentów, nauczycieli, studiów w Instytucie Dziennikarstwa i Komunikacji Społecznej (dalej: IDIKS) dotyczy nowej dyscypliny naukowej z zakresu nauk społecznych, jaką są nauki o komunikacji społecznej i mediach ${ }^{4}$.

\section{STUDIUM PRZYPADKU - PROCES UMIĘDZYNARODOWIENIA Instytutu Dziennikarstwa i Komunikacji Spolecznej}

Instytut Dziennikarstwa i Komunikacji Społecznej na Uniwersytecie Papieskim Jana Pawła II w Krakowie to jednostka prowadząca kierunek dziennikarstwo i komunikacja społeczna na studiach pierwszego i drugiego stopnia w trybie stacjonarnym i niestacjonarnym.

W ciągu 10 lat swojego istnienia Instytut realizował różne formy współpracy międzynarodowej na poziomie mobilności studentów i wykładowców, a także uczestnicząc

\footnotetext{
${ }^{3}$ Por. podział zaproponowany: B. Siwińska, G. Mazurek, Wstęp, w: Czas internacjonalizacji II. Perspektywy, priorytety, projekty, red. B. Siwińska, G. Mazurek, Warszawa 2017, s. 8.

${ }^{4}$ Rozporządzenie Ministra Nauki i Szkolnictwa Wyższego z dnia 20 września 2018 roku w sprawie dziedzin nauki i dyscyplin naukowych oraz dyscyplin artystycznych.
} 
w różnych projektach międzynarodowych. Warto zaznaczyć kilka ważnych obszarów tej współpracy, która dotyczy w dużej mierze kontaktów pracowników naukowych $\mathrm{z}$ różnymi uniwersytetami, przede wszystkim w Europie. Warto wymienić następujące formy tej współpracy:

- Program Erasmus+

- Program CEEPUS

- Współpraca wyszehradzka V4

- Projekty Unii Europejskiej

- Projekty NAWA

- Współpraca bilateralna między uczelniami

- Wykłady kadry zagranicznej na uniwersytecie

- Organizowane konferencje międzynarodowe.

Dziesięciolecie Instytutu jest okazją także do spojrzenia na specyfikę i dynamikę procesu jego umiędzynarodowienia. Daje to możliwość dostrzeżenia obszarów najintensywniejszego rozwoju internacjonalizacji, a także diagnozy ewentualnych niepowodzeń lub trudności z wdrażaniem umiędzynarodowienia w konkretnych formach i na konkretnych polach działalności instytutu.

\section{Program Erasmus+}

W okresie istnienia Instytutu Dziennikarstwa i Komunikacji Społecznej Uniwersytetu Papieskiego zostały nawiązane i podpisane umowy o współpracy naukowo-badawczej oraz wymiany dydaktycznej studentów i kadry akademickiej z następującymi uniwersytetami: University of Limerick, Irlandia; Universidade Catolica Portuguesa, Portugalia; Catholic University in Ruzomberok, Słowacja; Universita degli Studi „Suor Orsola Benincasa", Włochy; Vilniaus universitetas, Litwa; Universidad Complutense de Madrid, Hiszpania; Universita Cattolica del Sacro Cuore, Włochy; Universidad a Distancia de Madrid, Hiszpania; University of Pisa, Wlochy; Univerza v Ljubljania, Słowenia; Universidade Lusófona de Humanidades e Tecnologias, Lizbon, Portugalia; Institut Catholique de Toulouse, Francja; Instituto Politechnico de Lisboa, Portugalia; University of Perugia, Włochy; University of Bremen, Niemcy; Universidad Abat Oliba CEU, Hiszpania; Universidade de Santiago de Compostela, Hiszpania; Otto-Friedrich-Universität Bamberg, Niemcy; The University for Foreigners Perugia, Włochy;; Universidade Lusófona do Porto, Portugalia; The University of Applied Sciences Burgenland, Austria; University of Ostrava, Czechy; Catholic University of Croatia, Chorwacja $^{5}$.

Instytut Dziennikarstwa i Komunikacji Społecznej jest od lat najczęściej wybieranym instytutem do realizacji studiów w ramach programu Erasmus+ przez studentów zagranicznych i studentów wyjeżdżających. Od kilku lat spośród wszystkich studentów zagranicznych przyjeżdżających na Uniwersytet Papieski Jana Pawła II w Krakowie

\footnotetext{
${ }^{5}$ Program Erasmus+, www.upjp2.edu.p1/Erasmus (5.05.2019).
} 
znacznie ponad połowę stanowią studenci, którzy wybierają kierunek dziennikarstwo i komunikacja społeczna. Ten fakt sprawia, że zarówno studenci polscy, jak i pracownicy naukowo-dydaktyczni i dydaktyczni mieli okazję współpracy z licznym gronem studentów zagranicznych. Był to z pewnością jeden z impulsów, który przyczynił się do istotnego wzrostu zainteresowania wyjazdami w ramach programu Erasmus+ wśród nauczycieli akademickich, a przede wszystkim wpłynął na popularność tego programu wśród polskich studentów (np. spośród 21 studentów ubiegających się o wyjazd na stypendium w roku akademickim 2019/2020 20 reprezentowało Instytut Dziennikarstwa i Komunikacji Społecznej) ${ }^{6}$.

Z czasem dużą renomę (zwłaszcza pośród studentów, którzy odbyli semestr studiów w uczelniach zagranicznych w ramach Erasmus+) zyskał program praktyk studenckich i absolwenckich proponowany przez ten program. Wyjazdy na praktyki stanowily dla wielu studentów ważne uzupełnienie ich edukacji uniwersyteckiej.

Uczestnictwo w programie Erasmus+ zdecydowanie wpłynęło na wzrost wśród studentów tych kompetencji, które można nabyć podczas pobytu zagranicą (należą do nich m.in. kompetencje językowe, ale przede wszystkim kompetencje komunikacyjne i kulturowe $)^{7}$. Studenci traktują wyjazd na stypendium jako szansę na rozwój osobisty, intelektualny i wzbogacenie swojego CV o ważny dla potencjalnego pracodawcy aspekt.

\section{Program CeEPUS}

W ostatnich dwóch latach Instytut zainteresował się możliwościami oferowanymi przez Central European Exchange Program for University Studies. Program umożliwia „intensyfikację kontaktów między szkołami wyższymi krajów będących stronami Porozumienia poprzez finansowanie mobilności akademickiej" ${ }^{8}$. Zainteresowanie programem CEEPUS zaowocowało uczestnictwem $\mathrm{w}$ dwu sieciach akademickich CEEPUS:

1. CEEPUS Network III, od 2018: Title of CEEPUS III network: SK-1315 Shared History of Central Europe, Coordinator of the whole network: Matej Bel University Banska Bystrica, Faculty of Arts, Matej Bel University, PhDr., PhD. Anton Hrubon, Name of university: The Pontifical University of John Paul II in Cracow, Name of local network partner: The Pontifical University of John Paul II in Cracow, Institute of Journalism and Social Communication, prof. Michał Drożdż.

2. CEEPUS Network III od 2019: Title of CEEPUS III network: AT-0050 Education Without Frontiers, Coordinator of the whole network: Mag. Lenka Kovarik, University of Applied Sciences Burgenland, International Business Relations, Name of university:

\footnotetext{
${ }^{6}$ Archiwum prywatne (10.05.2019).

${ }^{7}$ Por. The Erasmus Impact Study. Effects of mobility on the skills and employability of students and the internationalisation of higher education institutions, EU 2014, https://ec.europa.eu/programmes/erasmus-plus/ sites/erasmusplus2/files/erasmus-impact_en.pdf (05.05.2019).

${ }^{8}$ Program CEEPUS - Środkowoeuropejski Program Wymiany Uniwersyteckiej, https://nawa.gov.pl/naukowcy/ceepus (5.05.2019).
} 
The Pontifical University of John Paul II in Cracow, Institute of Journalism and Social Communication, Name of local network partner: The Pontifical University of John Paul II in Cracow, Institute of Journalism and Social Communication, prof. Michał Drożdż .

Ponadto pracownicy Instytutu realizowali stypendia CEEPUS w ramach programu Freemover, nawiązując kolejne kontakty w środowiskach akademickich Europy Środkowej, a przede wszystkim zyskując doświadczenia pracy dydaktycznej w jednostkach zagranicznych. Między innymi te kontakty umożliwiły przygotowanie aplikacji dotyczącej stworzenia nowej sieci akademickiej koordynowanej przez IDIKS pod tytułem Media and Social Communication. Powstanie tej sieci oraz jej rozwój będzie dla Instytutu szansą na umiędzynarodowienie badań, a także spełni rolę prestiżową - umiędzynarodowienia wizerunku jednostki, jako organizatora i koordynatora pierwszej sieci akademickiej CEEPUS w dyscyplinie nauki o mediach i komunikacji społecznej.

\section{VISEGRAD FUND}

Współpraca wyszehradzka V4 jest kolejną płaszczyzną relacji pomiędzy uniwersytetami, w którą zaangażował się IDIKS. Pierwszym projektem z tej grupy jest projekt pt. Development of Urban Culture in V4 Countries (2019) koordynowany przez Uniwersytet Mateja Beja w Bańskiej Bystrzycy. Razem z partnerami z University of Miskolc (Węgry), Czech University of Life Sciences (Czechy) oraz Uniwersytetem Papieskim Jana Pawła II w Krakowie realizowany jest kilkuetapowy projekt, który polega na promocji kultury miejskiej w sieci poprzez tworzenie interaktywnych map, wykorzystaniu nowych narzędzi medialnych do promocji kultur lokalnych. Projekt obejmuje także konferencje międzynarodowe i wykłady gościnne. Jest działaniem wpływającym na umiędzynarodowienie jednostek partnerskich, a jednocześnie jest przykładem interdyscyplinarnych badań i działań wykonywanych przez jednostki uczestniczące w projekcie.

Równie obiecującym wydaje się zaangażowanie IDIKS UPJP2 w realizację grantu wyszehradzkiego The past forges future in the neighbourhood of V4+ koordynowanego przez University The College of Bussines in Prague, wraz z trzema partnerami: College of Public Administration, Economics and Management (Słowacja), Union Nicola Tesla University (Serbia). W ramach tego projektu będzie zrealizowana ciekawa inicjatywa: Internship VŠO and UPJPJII Summer School „New communication of culture - challenge for the tourist market in the Visegrad group - examples from Prague and Cracow” 2020. Współpraca z partnerami zapowiada się obiecująco, dając nadzieję zarówno na pomyślną realizację bieżącego grantu, jak i na przyszłą współpracę, zwłaszcza w zakresie komunikowania marketingowego i promocyjnego.

\footnotetext{
${ }^{9}$ Archiwum prywatne (10.05.2019).
} 


\section{Projekty Unit Europejskiej}

W historii Instytutu Dziennikarstwa i Komunikacji Społecznej zrealizowano kilka poważnych projektów w ramach finansowania Unii Europejskiej. Były to zarówno projekty szkoleniowe, jak i bardzo duże granty infrastrukturalne, a także projekty dydaktyczno-stażowe przygotowywane dla studentów, by zwiększyć ich potencjał na rynku pracy. Do projektów IDIKS realizowanych w ramach finansowania Unii Europejskiej należą m.in.:

- Program SONETOR - Training of Cultural Mediators Utilizing New Social Networking Software (szkolenie mediatorów kulturowych $\mathrm{z}$ wykorzystaniem nowego sieciowego oprogramowania społecznościowego). Jest to program Unii Europejskiej: Leonardo da Vinci (LLP), podprogram: Projekty wielostronne - rozwój innowacyjności, jednostka koordynująca: Hellenic Open University (Grecja), poza UPJPII członkami konsorcjum są: Uniwersytet w Limerick (Irlandia), Research Academic Computer Technology Instistute w Patras, MARQUE 21 SL (Hiszpania) i BEST Institut für berufsbezogene Weiterbildung und Personaltra (Austria). Okres realizacji projektu: luty 2012 - styczeń 2014.

- Projekt - Modernizacja infrastruktury badawczo-dydaktycznej, z uwzględnieniem potrzeb studentów niepetnosprawnych. Projekt w konkursie Narodowego Centrum Badań i Rozwoju, Oś Priorytetowa Małopolskiego Regionalnego Programu Operacyjnego - Warunki dla rozwoju społeczeństwa opartego na wiedzy, 1.1 Poprawa jakości usług edukacyjnych, Schemat A: Rozwój infrastruktury dydaktycznej szkolnictwa wyższego, całkowita [wartość projektu: 1492 780,24,-], od 30 sierpnia 2012 do 31 maja 2014 roku.

- Projekt Modernizacja infrastruktury medialno-technicznej dla potrzeb innowacyjnego kształcenia i aktywizacji zawodowej w zakresie nowych mediów w społeczeństwie informacyjnym. Projekt w konkursie Narodowego Centrum Badań i Rozwoju, Małopolski Regionalny Program Operacyjny 2007-2013, Oś Priorytetowa Małopolskiego Regionalnego Programu Operacyjnego - Warunki dla rozwoju społeczeństwa opartego na wiedzy, Zadanie 1.1. Poprawa jakości usług edukacyjnych, Schemat A: Rozwój infrastruktury dydaktycznej szkolnictwa wyższego, Numer Projektu: MRPO.01.01.01-12-026/15 [wartość projektu: 1712 004,921,-], 2015-2016.

- Projekt Staże dla studentów dziennikarstwa i komunikacji społecznej Uniwersytetu Papieskiego Jana Pawła II w Krakowie. Projekt w konkursie Narodowego Centrum Badań i Rozwoju, nr POWR.03.01.00-S129/17, współfinansowany ze środków Europejskiego Funduszu Społecznego, w ramach Programu Operacyjnego Wiedza Edukacja Rozwój, numer i nazwa Osi priorytetowej: III. Szkolnictwo wyższe dla gospodarki i rozwoju, numer i nazwa Działania: 3.1 Kompetencje w szkolnictwie wyższym, realizowany na podstawie umowy o dofinansowanie nr: POWR.03.01.00-S129/17-00, z dnia 03.11.2017 roku, [wartość projektu: 974 719,50,-], od 1 października 2017 roku do 30 kwietnia 2019 roku.

- Projekt Skonsolidowane Programy Uczelni (SPR). Projekt w konkursie Narodowego Centrum Badań i Rozwoju, projekt współfinansowany przez Unię Europejską 
ze środków Europejskiego Funduszu Społecznego w ramach Programu Wiedza Edukacja Rozwój 2014-2020; opracowanie i nadzór realizacyjny 29 akademii podnoszenia kompetencji studentów i kadry dydaktycznej Akademickiego Centrum Medialnego w ramach Skonsolidowanego Programu Rozwoju Uniwersytetu Papieskiego Jana Pawła II w Krakowie [wartość projektu: 6960 118,81-,], od 1 września 2018 roku do 31 sierpnia 2022 roku $^{10}$.

\section{WSPÓŁPRACA Z ZAGRANICZNYMI UNIWERSYTETAMI W RAMACH MEDIOZNAWCZYCH KONFERENCJI NAUKOWYCH}

Jedną z najbardziej podstawowych form kontaktu naukowego są konferencje naukowe. Te o charakterze międzynarodowym dają szansę na wymianę myśli pomiędzy ośrodkami badawczymi, a także służą organizowaniu wspólnych publikacji naukowych. Instytut Dziennikarstwa angażował się w tę formę umiędzynarodowienia szkolnictwa wyższego w zakresie kształcenia medialnego, organizując i współorganizując liczne spotkania konferencyjne. Wśród nich są m.in.:

- 13 edycji Konferencji Etyki Mediów (od 2008 roku), w których uczestniczą także osoby z zagranicznych uniwersytetów, szczególnie ze Słowacji, Czech i Austrii, Stanów Zjednoczonych.

- IV Międzynarodowa Konferencja Global Communication Association Globalization, Culture and Education in the Information Age, Kraków, 26-29 października 2010 roku. Konferencję zorganizował Instytut Dziennikarstwa i Komunikacji Społecznej Uniwersytetu Papieskiego Jana Pawła II w Krakowie we współpracy z Katolickim Uniwersytetem Lubelskim oraz Collegium Civitas i amerykańskim Pardue University. Uczestniczyli naukowcy i praktycy w dziedzinie mediów z 12 krajów (m.in. z USA, Japonii, Omanu, Malezji, Indii, Iranu, Turcji, Wielkiej Brytanii, Malty, Finlandii).

- IV Central and Eastern European Communication and Media Conference (CEECOM) Convergence: Media in Future - Future in Media, Kraków, 5-7 maja 2011 roku. Organizatorem konferencji był Instytut Dziennikarstwa i Komunikacji Społecznej Uniwersytetu Papieskiego Jana Pawła II, współorganizatorem było Polskie Towarzystwo Komunikacji Społecznej. IV CEECOM 2011 było kontynuacją 3 poprzednich spotkań (Wrocław 2008, Brno 2009, Bratysława 2010).

- Międzynarodowa Konferencja Programowa w projekcie Romska Akademia Mediów, Kraków, 21 listopada 2013 roku, Uniwersytet Papieski Jana Pawła II w Krakowie. Celem konferencji było budowanie dialogu pomiędzy społecznościami romskimi i nieromskimi. Wszelkie działania są ściśle związane z rozwijaniem spojrzenia na człowieka w aspekcie jego godności i tworzenia dobrych relacji w szczególnej przestrzeni społecznej, gdzie żyją Romowie i Nieromowie. W czasie konferencji

10 Archiwum prywatne (10.05.2019). 
zaprezentowano badania socjologiczne prowadzone w społecznościach romskich oraz serię programów telewizyjnych wyprodukowanych na cele Romskiej Akademii Mediów.

- I Międzynarodowa Konferencja Naukowa Man for the Media or the Media for Man?, Instytut Dziennikarstwa i Komunikacji Społecznej Uniwersytetu Papieskiego Jana Pawła II w Krakowie, 7 grudnia 2017 roku. W czasie konferencji wygłosiły referaty m.in.: prof. Maria Inacia Rezola: The media role in the history perspective of XX century, prof. Maria Joao Centeno: Fake news - the role of the social media, prof. Fernanda Bonacho: The responsibility of the journalistic discourse in contemporary media.

- II Międzynarodowa Konferencja Naukowa z cyklu „Man for Man” Lost or found in Web, Instytut Dziennikarstwa i Komunikacji Społecznej Uniwersytetu Papieskiego Jana Pawła II w Krakowie, 5 grudnia 2018 roku. W ramach konferencji wygłoszono m.in. następujące referaty: The Perils and Promise of Recommendation Algorithmsdr, Chris Ingraham, University of Utah (USA), Fulbright Professor in Digital Culture at the University of Bergen (Norway); Losing Innocence and Finding Justice in the Age of the Internet, prof. Anne Driscoll, Brandeis University (USA), Fulbright Scholar Communications at the National University of Ireland in Galway (Ireland); Social Responsibility in Action on the World Wide Web Dr. Janis Teruggi Page, The George Washington University (USA), Fulbright Scholar in Communications at Masaryk University (The Czech Republic); Lose-lose or win-win? Children and young people interacting on the Internet dr. Pavel Izrael, Head of Department of Journalism at Catholic University in Ružomberok (Slovakia).

- III Międzynarodowa Konferencja Naukowa z cyklu „Man for Man”. Real Values in the Virtual World, Instytut Dziennikarstwa i Komunikacji Społecznej Uniwersytetu Papieskiego Jana Pawła II w Krakowie, 4 grudnia 2019 roku. W ramach konferencji wygłoszono m.in. następujące referaty: PhDr. Ivana Bulanda, PhD. (Vice-rector College of Business and Law, Prague, Czech Republic) Attractiveness in a virtual World (part I), Ing. Vladimír Vavrečka, CSc., (College of Business and Law, Prague, Czech Republic), Attractiveness in a virtual World (part II), Doc. Terézia Rončáková, PhD., (Catholic University in Ruzomberok, Slovakia) Religious Messages in the Media Case Study of Celebrity Gossip Column „Virtues and Vices” ${ }^{11}$.

Projekt cyklu międzynarodowych konferencji Media for Man okazał się bardzo udaną, twórczą i owocną inicjatywą. Kontakty nawiązane z uczestnikami skutkują również współpracą na innych polach (wspólne publikacje, zaproszenia do grantów). Projekt ten z pewnością będzie kontynuowany. Stał się on już drugim (obok cyklu Konferencji Etyki Mediów), w pełni międzynarodowym, znakiem rozpoznawczym IDIKS. Oczywistym uzupełnieniem tej sfery działalności Instytutu jest uczestnictwo jego pracowników w licznych konferencjach zagranicznych.

${ }^{11}$ Archiwum prywatne (10.05.2019). 


\section{WSPÓŁPRACA BILATERALNA MIĘDZY UCZELNIAMI}

$\mathrm{W}$ ramach podpisanych umów partnerskich $\mathrm{z}$ uczelniami w Europie (szczególnie w grupie V4 i Austrii) IDIKS realizuje lub planuje następujące formy współpracy:

- wizyty oficjalne kierownictw jednostek w uczelniach i instytucjach zagranicznych;

- podejmowanie przedstawicieli uniwersytetów zagranicznych i innych gości Instytutu;

- uczestnictwo zespołów badawczych i pracowników Instytutu w grantach międzynarodowych oraz w programach badawczych;

- uczestnictwo indywidualne pracowników i studentów w projektach badawczych;

- wymianę doświadczeń i wzajemne zaproszenia w zakresie publikacji naukowych

z partnerami zagranicznymi;

- wyjazdy krótkoterminowe pracowników i studentów do uczelni zagranicznych;

- przyjazdy pracowników, stażystów i studentów z uczelni zagranicznych na wizyty studyjne;

- uczestnictwo w międzynarodowych konferencjach, seminariach i szkoleniach;

- współorganizowanie konferencji naukowych;

- kontakty z zagranicznymi przedstawicielstwami dyplomatycznymi w Polsce (szczególnie z Konsulatem Generalnym Stanów Zjednoczonych w Krakowie, Konsulatem Generalnym Republiki Francuskiej w Krakowie);

- udział przedstawicieli w komitetach międzynarodowych organizacji oraz radach naukowych czasopism.

\section{Podsumowanie - ZADANiA I WyZWANiA}

W kontekście opisanych powyżej działań i w obliczu zbliżającej się parametryzacji w szkolnictwie wyższym Instytut, jak każda jednostka, musi stanąć przed nowymi wyzwaniami.

Ważnym zadaniem stojącym przez IDIKS jest poszerzenie oferty angielskojęzycznej (docelowo stworzenie kierunku w języku angielskim), co umożliwi napływ większej liczny studentów zagranicznych i realizację procesów umiędzynaradawiania Uniwersytetu na tym polu, aktualnie intensywnie rozwijanym w szkolnictwie polskim ${ }^{12}$. Obecnie IDIKS oferuje 10 kursów w języku angielskim w ciągu roku akademickiego.

W sytuacji, gdy poziom umiędzynarodowienia z perspektywy parametryzacji jest określany na podstawie arbitralnie wyznaczonych wytycznych (np. brak wzięcia pod uwagę międzynarodowych projektów dydaktycznych i infrastrukturalnych) konieczna jest intensyfikacja w zakresie pozyskiwania międzynarodowych grantów badawczych,

12 Por. I. Bień, Studenci zagraniczni w Polsce, „Analizy. Biuro Analiz Sejmowych” (2018) nr 1 (147). 
które spełnią wymogi oceny efektów finansowych badań naukowych z uwzględnieniem choćby projektów finansowanych przez przedsiębiorców ${ }^{13}$.

Warte rozwijania będą kontakty międzynarodowe poza siecią Erasmus+ (w związku z bardzo małą pulą wyjazdów dostępną dla nauczycieli akademickich UPJPII), tak, by aktywność naukowa nie była ograniczana względami proceduralnymi. Obok wzmiankowanych powyżej inicjatyw instytucjonalnych na szczęście rozwija się także indywidualna działalność badawcza pracowników, którzy dbają o umiędzynarodowienie swojego dorobku i korzystają z możliwości, jakie dają NCN czy NAWA. Dotychczasowe działania IDIKS w zakresie nawiązywania nowych kontaktów w zagranicznym medioznawczym środowisku akademickim okazują się owocne i pozwalają patrzeć w przyszłość z nadzieją na wzrost umiędzynarodowienia tej jednostki.

\section{LITERATURA}

Archiwum prywatne (10.05.2019).

Antonowicz D., Lepsze jutro było wczoraj, czyli mity dotyczące umiędzynarodowienia szkolnictwa wyższego, w: Czas internacjonalizacji II. Perspektywy, priorytety, projekty, red. B. Siwińska, G. Mazurek, Warszawa 2017.

Bień I., Studenci zagraniczni w Polsce, „Analizy. Biuro Analiz Sejmowych” (2018) nr 1 (147).

Mazurek G., Zarządzanie uczelniq międzynarodowa - perspektywa krajowa - Akademia Leona Koźmińskiego, w: Czas internacjonalizacji. Wyzwania dla polskich uczelni, red. B. Siwińska, M. Zimnak, Warszawa 2016.

Siwińska B., Mazurek G., Wstęp, w: Czas internacjonalizacji II. Perspektywy, priorytety, projekty, red. B. Siwińska, G. Mazurek, Warszawa 2017.

Program CEEPUS - Środkowoeuropejski Program Wymiany Uniwersyteckiej, https://nawa.gov. $\mathrm{pl} /$ naukowcy/ceepus (5.05.2019).

Program Erasmus+, www. upjp2.edu.pl/Erasmus (5.05.2019).

Rozporządzenie Ministra Nauki i Szkolnictwa Wyższego z dnia 20 września 2018 r. w sprawie dziedzin nauki i dyscyplin naukowych oraz dyscyplin artystycznych, http://prawo.sejm.gov.pl/ isap.nsf/download.xsp/WDU20180001818/O/D20181818.pdf (5.05.2019).

The Erasmus Impact Study. Effects of mobility on the skills and employability of students and the internationalisation of higher education institutions, EU 2014, https://ec.europa.eu/programmes/ erasmus-plus/sites/erasmusplus2/files/erasmus-impact_en.pdf (5.05.2019).

Ustawa z dnia 20 lipca 2018 r. Prawo o szkolnictwie wyższym i nauce, http://prawo.sejm.gov. pl/isap.nsf/download.xsp/WDU20180001668/U/D20181668Lj.pdf (5.05.2019).

13 Ustawa z dnia 20 lipca 2018 r., Prawo o szkolnictwie wyższym i nauce, http://prawo.sejm.gov.pl/isap. nsf/download.xsp/WDU20180001668/U/D20181668Lj.pdf (5.05.2019). 